JURNAL HUMANIORA

TEKNOLOGI

Vol. 1 No.1 ; Oktober 2015

\title{
ANALISIS MINAT ANAK USIA DINI DALAMBELAJAR VOCABUALRY DENGAN MEMANFAATKAN GOOGLE TRANSLATE(NATIVE SOUNDS) (STUDI KASUS PADA PAUD)
}

\author{
WAN YULIYANTI \\ Staff pengajar Bahasa Inggris, Politeknik Negeri Tanah Laut \\ Jl. A. Yani Km. 6 Ds. Panggung Kec. Pelaihari Kab. Tanah Laut, Kalimantan Selatan \\ Korespodensi: \\ Telepon/nomor faks : +6281316889967 / 0512-21537 \\ E-Mail : : wanyuliyanti@gmail.com
}

\begin{abstract}
Abstrak
Tulisan ini merupakan kelanjutan dari Pengabdian kepada Masyarakat (PkM) yang penulis laksanakan di Kecamatan Pelaihari Kabupaten Tanah Laut Kalimantan Selatan berjudul: "PELATIHAN PEMANFAATAN INTERNET GOOGLE TRANSLATE DALAM MENCARI NATIVE SOUNDS SEBAGAI MEDIA PENGAJARAN AUDIO-VISUAL VOCABULARY UNTUK GURU PAUD”.

Penulis meyakini bahwa media ini dapat meningkatkan minat anak usia dini dalam belajar Bahasa Inggris dimulai dari mengenal vocabulary, terutama bagi mereka yang tinggal di daerah terpencil di salah satu kabupaten di Kalimantan Selatan.

Selain mudah dibuat, media ini sangat membantu para guru yang tidak memiliki latar belakang pendidikan Bahasa Inggris, sehingga lebih percaya diri dalam mengajarkan vocabulary kepada anak usia dini. Media ini tidak hanya mengandung unsur visual berupa gambar-gambar dengan bentuk dan warna yang indah, namun juga mengandung unsur audio (native sounds) sehingga sangat menarik bagi anak usia dini yang belum diajarkan baca-tulis dan berhitung.

Tinggi rendahnya minat anak dapat melalui penilaian yang memiliki indikator penilaian melalui tahapan: (1)pre-test, (2)pengajaran dan (3)post-test, dengan category hasil belajar: Fair, Good, Very Good atau Excellent dengan scoring persentase (\%).

Materi yang diberikan dan diukur adalah berdasarkan scope, antara lain: color, shape, fruit, vegetable, animal, transportation, dan numbers up to twenty yang diberikan secara berulang melalui slideshow.
\end{abstract}

Kata Kunci: minat, anak usia dini, vocabulary-scope, audio-visual 


\section{PENDAHULUAN}

\section{Latar Belakang}

Pendidikan Anak UsiaDini (PAUD) sekarang ini telah banyak bermunculan di masyarakat, baik dalam bentuk formal maupun nonformal. Hal ini ditandai dengan banyaknya lembaga PAUD yang bermunculan di berbagai daerah.Kabupaten Tanah Laut, Kalimantan Selatan sendiri merupakan daerah yang memiliki \pm 200 buah sekolah bagi anak usia dini (PAUD). Namun yang menjadi perhatian khusus adalah sudahkah desain pembelajaran di lembaga PAUD di Indonesia, khususnya di Kabupaten Tanah Laut memenuhi standar yang digariskan oleh undang-undang pendidikan yang tentu saja sudah diadaptasi dari kebutuhan pendidikan anak usia dini?

Umumnya, diperlukan sebuah acuan tentang bagaimana desain pembelajaran yang tepat agar tujuan dari pendidikan di usia dini dapat dicapai, sehingga anak pada masa usia dini ini lebih dikenal dengan masa the golden age. Pada masa ini perkembangan dan pertumbuhan pada anak dapat dimaksimalkan dengan memberikan stimulasi yang baik, akan memudahkan anak dalam proses pendidikan selanjutnya (Fadlillah, 2012:5).

Menurut Devianti (2013:9-10), pembelajaran bagi anak usia dini belum dapat dituntut untuk berfikir secara logis, sehingga dianjurkan lebih ke arah yang bersifat:

a. Berfikir secara konkrit, dimana anak belum dapat memahami atau memikirkan hal-hal yang bersifat abstrak (seperti cinta atau keadilan)

b. Realisme, yaitu kecenderungan yang kuat untuk menanggapi segala sesuatu sebagai hal yang riil atau nyata.

c. Egosentris, yaitu melihat segala sesuatu hanya dari sudut pandangnya sendiri dan tidak mudah menerima penjelasan dari sisi lain.

d. Kecenderungan untuk berfikir sederhana dan tidak mudah menerima sesuatu yang majemuk.

e. Animisme, yaitu kecenderungan untuk berfikir bahwa semua objek yang ada dilingkungannya memiliki kualitas kemanusiaan sebagaimana yang dimiliki anak.

f. Sentrasi, yaitu kecenderungan untuk mengkonsentrasikan dirinya pada satu aspek dari suatu situasi.

g. Anak usia dini dapat dikatakan memiliki imajinasi yang sangat kaya dan imajinasi ini sering dikatakan sebagai awal munculnya bibit kreativitas pada anak.

Dari penjelasan di atas, dapat disimpulkan bahwa anak usia dini sangat membutuhkan suatu media pembelajaran yang tepat sesuai dengan masa the golden age mereka. Adapun 
media pembelajaran yang tepat bagi the golden age antara lain adalah pembelajaran dengan media audio-visual. Media ini dianggap dapat semaksimal mungkin meningkatkan kosa kata anak usia ini atau lebih tepatnya media pembelajaran yang dapat digunakan dalam pengajaran Bahasa Inggris.

Pengajaran Bahasa Inggris, vocabulary, bagi PAUD, tampak kurang mendapat perhatian bagi pengelola ataupun guru-guru PAUD. Hal ini dikarenakan kurangnya tenaga pengajar/guru dengan latar belakang Pendidikan Bahasa Inggris, sehingga banyak guru yang kurang berani dan kurang percaya diri dalam mengajar Bahasa Inggris. Pada dasarnya, hal ini dapat dihindari jika guru-guru memiliki metode pembelajarandan pembelajaran yang tepat dalam mengajarkan vocabulary tersebut walaupun mereka tidak memiliki latar belakang Pendidikan Bahasa Inggris. Adapun media pembelajaran yang dapat digunakan adalah dengan menggunakan Metode Pengajaran Audio-Visual, yaitu dengan cara men-download suara dari native speaker dengan menggunakan media internet (Google translate). Sehingga semua guru dapat mengajar Bahasa Inggris terutama vocabulary, tanpa mengkhawatirkan latar belakang pendidikan mereka. Karena para guru dapat menampilkan suara (audio) dan gambar (visual) kepada anak dengan menampilkannya melalui LCD Projector/in focus dari komputer atau laptop sesuai dengan tema/ruang lingkup (scope) yangsedang dipelajari di PAUD.

\section{Perumusan Masalah}

Berhubung penelitian adalah merupakan kelanjutan dari PkM penulis, maka masalahmasalah yang terkait dalam penelitian ini adalah:"Sejauh mana minat anak usia dini belajar vocabulary diukur dari hasil pre-test dan post-test dengan menggunakan media pembelajaran vocabulary denganaudio-visual?"

\section{Tinjauan Pustaka}

Pengajaran Bahasa Inggris bagi anak pada masa the golden age dengan menggunakan media pembelajaranaudio-visual merupakan hal yang sangat tepat dalam mengaktifkan otak kiri dan otak kanan, dimana yang menyangkut otak kiri antara lain dari aspek bahasa dan logika, sedangkan otak kanan dari aspek imajinasi visual, kreatifitas dan bentuk. Sehingga pengajaran vocabulary dengan mediaaudio-visual merupakan media pembelajaran yang paling tepat. 


\section{A. Media Pembelajaran}

Media pembelajaran sangat dibutuhkan anak usia dini karena mereka tidak diajarkan membaca, menulis dan berhitung diusianya.

Media merupakan suatu alat/sarana yang digunakan untuk menyampaikan suatu berita atau informasi.National Education Association (NEA), mengatakan bahwa "media" adalah bentuk-bentuk komunikasi baik cetak maupun audio-visual serta peralatannya.

Media pembelajaran saat ini semakin diperlukan baik oleh guru maupun murid/siswa mulai dari usia dini sampai ke perguruan tinggi. Menurut Sanaky (2011:3), media pembelajaran adalah sebuah alat yang berfungsi dan digunakan untuk menyampaikan pesan pembelajaran.

Dalam kegiatan pembelajaran, media pada umumnya sangat berfungsi dalam pencapaian tujuan pembelajaran secara efektif dan efisien. Lebih jauh lagi Sanaky (2011:6) mengungkapkan bahwa media pembelajaran berfungsi untuk merangsang pembelajaran dengan:

1. Menghadirkan obyek sebenarnya dan obyek yang langka,

2. Membuat duplikasi dari obyek yang sebenarnya,

3. Membuat konsep abstrak ke konsep konkret,

4. Memberi kesamaan persepsi,

5. Mengatasi hambatan waktu, tempat, jumlah, dan jarak

6. Menyajikan ulang informasi secara konsisten, dan

7. Memberi suasana belajar yang tidak tertekan, santai, dan menarik, sehingga dapat mencapai tujuan pembelajaran.

\section{B. Internet}

Internet merupakan jaringan secara global yang dapat menghubungkan satu komputer ke komputer yang lainnya yang jumlahnya mencapai jutaan di lebih dari 100 negara di dunia.

Menurut Oxford Learner's Pocket Dictionary, internet adalah: international computer network connecting other networks and computers from companies, universities, etc.

\section{Metode Audio-Visual}

Metode audio-visual adalah metode yang digunakan dalam pembelajaran dengan memanfaatkan suara dan gambar demi kepentingan efektifitas dan efisiensi dalam proses 
belajar, terutama bagi anak usia dini. Adapun menurut sumber yang dikutip dari http://www.thefreedictionary.com/audio visual:

a. audiovisual - materials using sight or sound to present information; "language tapes and videocassettes and other audiovisuals"

b. audiovisual - involving both hearing and seeing (usually relating to teaching aids); "the school's audiovisual department"

c. (esp of teaching aids) involving or directed at both hearing and sight the language class had new audiovisual equipment

\section{Pengajaran Vocabulary Bagi Anak Usia Dini}

Secara umum,vocabulary berarti kosakata yang memiliki makna. Menurut Oxford Learner's Pocket Dictionary, vocabulary adalah:

a. All the words that a person knows or uses.

b. All the words in a language.

c. List of words with their meanings, esp in a book for learning a foreign language.

Pengajaran Bahasa Inggris, khususnya vocabulary untuk anak usia dini harus disesuaikan dengan kemampuan dan tahapan perkembangan mereka. Anak usia dini mempunyai kelebihan bahwa mereka suka menirukan dan mereka sering tidak menyadari dirinya sendiri dan biasanya mereka siap untuk menikmati kegiatan-kegiatan yang telah disiapkan oleh pengajar/guru untuk mereka. Dengan demikian, sangatlah mudah untuk mempertahankan tingkat motivasi yang tinggi dan membuat pengajaran Bahasa Inggris menjadi sesuatu yang biasa dinikmati dan merupakan pengalaman yang menyenangkan.Selain itu, hal perlu diingat adalah bahwa mengajarkan vocabulary baru tidak cukup satu kali dan kemudian selesai melainkan harus dilakukan berulang-ulang dalam konteks yang tepat.

Widi Herdiana menyatakan bahwa idealnya pembelajaran Bahasa Inggris pada anak usia dini menggunakan metode yang menyenangkan dengan media yang memiliki fitur audio (suara), visual (gambar) dan interaktif.

Selain masih terbatasnya media pembelajaran Bahasa Inggris yang mempunyai fitur audio-visual dan interaktif yang sesuai dengan kurikulum anak usiadini dan juga terbatasnya tenaga pengajar/guru yang memiliki latar belakang Pendidikan Bahasa (dan Sastra) Inggris, maka perlu kreatifitas guru untuk menciptakan suatu media pembelajaran yang efektif dan efisien. 


\section{E. Anak Usia Dini}

Umumnya, yang dikatakan anak usia dini adalah anak yang berusia 2-6 tahun dan berada pada tahap perkembangan awal masa kanak-kanak, yang memiliki karakteristik berpikir konkrit, realisme, sederhana dan kaya akan imajinasi. Sebagai mana kita ketahui bersama bahwa setiap anak yang dilahirkan di dunia pada dasarnya memiliki potensi yang sama. Hanya saja melalui proses pendidikan di lingkungan yang berbeda, menyebabkan potensi manusia yang satu dengan yang lain mengalami perbedaan. (Fadlillah, 2012:17).

Pendidikan anak usia dini pada dasarnya dan bertujuan untuk memberikan stimulasi pada perkembangan anak antara lain perkembangan fisik, intelektual, social, emosional dan perkembangan bahasa agar dapat berkembang secara optimal (Nurhadi:2012). Oleh karena itu pada anak usia dini tidak diperbolehkan adanya pembelajaran membaca dan menulis.

\section{Tujuan Penelitian}

Tujuan dari penelitianini adalalah:"Mengetahui sejauh mana media pembelajaranaudio-visual yang di-download dari google translatedapat meningkatkan minat anak usia dini dalam belajar vocabulary”.

\section{Manfaat Penelitian}

Melalui penelitian ini diharapkan manfaat yang akan diperoleh adalah:

1. Para guru PAUD di Kabupaten Tanah Laut lebih percaya diri dalam mengajar Bahasa Inggris, khususnya vocabulary walaupun tidak berlatar belakang pendidikan Bahasa Inggris

2. Media pengajaran ini meningkatkan minat anak usia dini dalam belajar Bahasa Inggris, khususnya vocabulary.

3. Native sounds yang di-download dari Google translate mambantu anak usia dini meningkatkan pronunciation dalam mengucapkan vocabulary Bahasa Inggris.

4. Media ini digunakan tidak hanya untuk pengajaran Bahasa Inggris saja, namun dapat pula digunakan untuk pengajaran materi-materi lainnya yang dibutuhkan bagi anak usia dini. 


\section{METODE PENELITIAN}

Agar dapat mengimplemetasikan media pengajaran yang akan digunakan maka diperlukan beberapa hal, yaitu perangkat keras dan perangkat lunak.

\section{Perangkat Keras}

Media pengajaran ini dibuat dengan menggunakan dan memanfaatkan perangkat keras (hardware) sebagai berikut:

1. Komputer/Laptop

2. Print out gambar (sesuai dengan scope)

3. In Focus/LCD Projector

4. Layar Monitor

5. Pengeras suara (USB speaker)

6. Wireless Presenter/Laser Pointer

\section{Perangkat Lunak}

1. MS. Office Powerpoint

2. Google Image (untuk mencari gambar)

3. Google Translate (untuk mencari suara Native speaker)

\section{Tahapan Penelitian}

Tahapan penelitian ini ada tiga tahap seperti tampak di bawah ini:

\begin{tabular}{|c|}
\hline I. Pemberian pre-test dan penilaian hasil pre-test \\
\hline \multicolumn{1}{|c|}{$\mid$} \\
\hline II. Pengajaran vocabulary dengan media Microsoft PowerPoint: Audio-Visual \\
\hline III.Post-test sebagai Assessment untuk mengukur penguasaan vocabulary anak \\
\hline
\end{tabular}

I. Tahap I: Pemberian pre-test untuk mengukur sejauh mana anak menguasai vocabulary untuk materi/scope yang akan diajarkan. 
Pre-test ini diberikan pada hari Senin dengan cara meminta anak menyebutkan gambar yang ditunjuk oleh pengajar/guru. Adapun alat ukur yang digunakan untuk mengetahui penguasaan vocabulary anak sebagai berikut:

Misalnya scope yang dipilih adalah shapes sebagai worksheet (lembar kerja) anak seperti tampak pada Gambar 3.1.dengan teknis sebagai berikut:

a. Guru memanggil anak satu persatu dan menulis nama anak pada lembar answerworksheet.

b. Guru menunjuk gambar satu persatu secara acak dan anak menyebutkan.

c. Guru mencatat jawaban anak pada kolom TRUE-FALSE

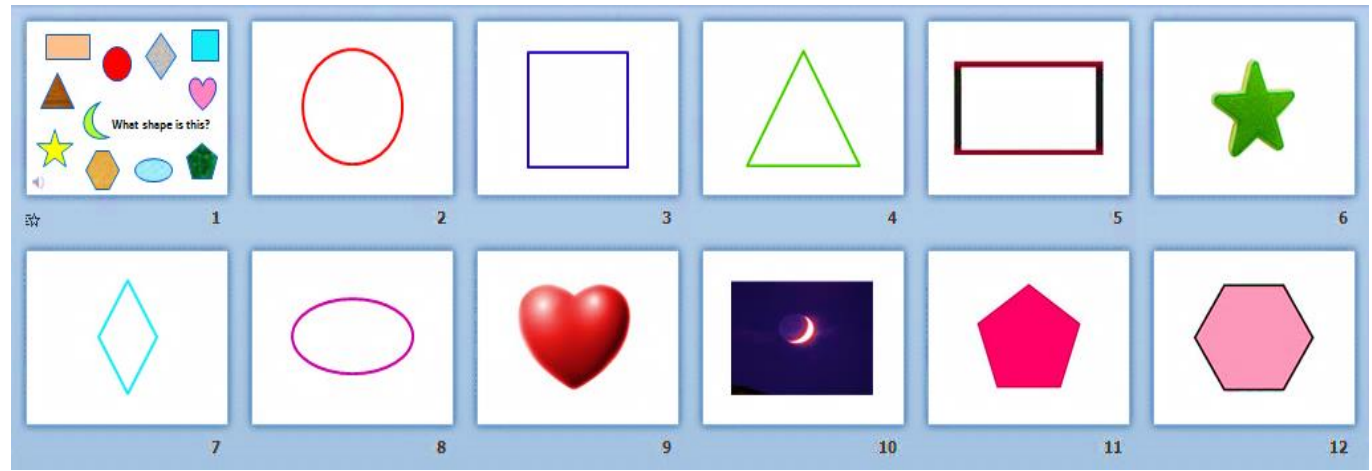

Gambar 2.1. Students' Worksheet

Berikut adalah contoh lembar jawaban anak (Gambar 2.2a dan 2b) sebagai panduan bagi guru untuk menilai kemampuan anak:

SCODE DF VDCABULARY

"SHAPES"

\begin{tabular}{|c|c|c|c|}
\hline No. & Vocabulary & $\sqrt{ }$ (true) & $\boldsymbol{X}$ (false) \\
\hline $\mathbf{1}$ & CIRCLE & & \\
\hline $\mathbf{2}$ & SQUARE & & \\
\hline $\mathbf{3}$ & TRIANGLE & & \\
\hline $\mathbf{4}$ & RECTANGLE & & \\
\hline $\mathbf{1}$ & STAR & & \\
\hline $\mathbf{6}$ & DIAMOND & & \\
\hline $\mathbf{7}$ & OVAL & & \\
\hline $\mathbf{8}$ & HEART & & \\
\hline $\mathbf{9}$ & PRESCENT & & \\
\hline $\mathbf{1 0}$ & HEXAGONON & & \\
\hline $\mathbf{1 1}$ & $\mathbf{2}$ & & \\
\hline
\end{tabular}

Gambar 2.2a. Lembar Jawaban untuk Scope "Shapes" 


\section{INTERVIEW: Mention the Vocabulary}

Interviewer's Name :

Student's Name :

\begin{tabular}{|c|c|c|c|c|}
\hline CATEGORY & 1: Fair & 2: GOOd & 3: Very Good & 4: Excellent \\
\hline $\begin{array}{c}\text { SCODE Of } \\
\text { Vocabulary }\end{array}$ & $\mathbf{0}-\mathbf{2 5 \%}$ & $\mathbf{2 6}-50 \%$ & $51-\mathbf{7 0} \%$ & $\mathbf{7 6}-\mathbf{1 0 0 \%}$ \\
"SHAPES" & & & \\
\hline
\end{tabular}

Gambar 2.2b. Lembar Jawaban untuk Category Kemampuan Anak

Adapaun category penilaian berdasarkan ruang lingkupnya (scope) masing-masing adalah sebagai berikut:

a. Fair: jika anak dapat menyebutkan $0-25 \%$ dari jumlah vocabulary

b. Good: jika anak dapat menyebutkan $26-50 \%$ dari jumlah vocabulary

c. Very Good: jika anak dapat menyebutkan $51-75 \%$ dari jumlah vocabulary

d. Excellent: jika anak dapat menyebutkan 76-100\% dari jumlah vocabulary

Maka akan dapat dinilai sejauh mana anak dapat menguasai media pembelajaran yang digunakan oleh guru. Alat ukur ini juga digunakan pada saat post-test.

II. Tahap II: Pengajaran/penyampaian materi vocabulary dengan media Microsoft PowerPoint: Audio-Visual Native Sound.

Penyampaian materi diberikan dengan caradrilling (diulang-ulang) pada hari Selasa, Rabu dan Kamis selama \pm 30 menit setiap harinya. Materi yang disajikan sebagai mana tampak pada Gambar 2.3.

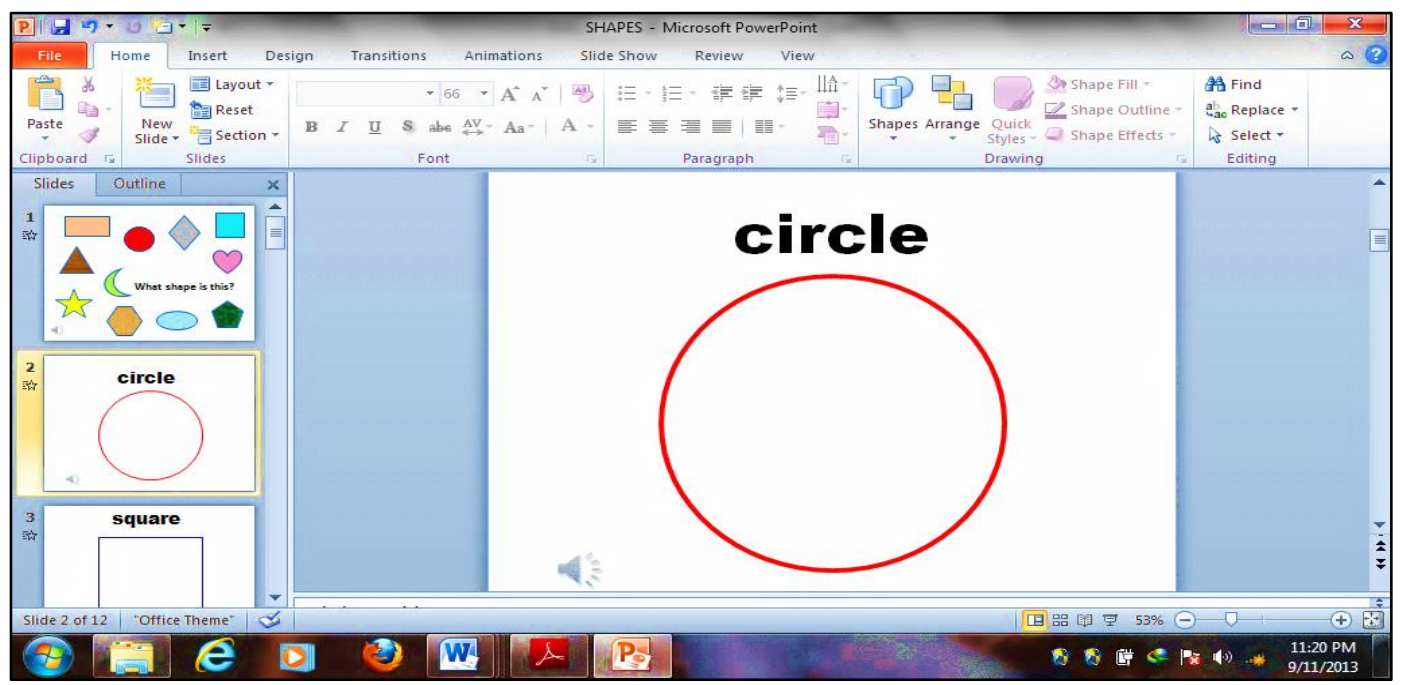

Gambar 2.3. Materi Ajar Shapes 
Penyampaian materi ini dilakukan dengan cara:

1. Pertama, bukalah materi ajar shapes (dalam bentuk PowerPoint) yang sudah disiapkan dengan cara mengklik F5 pada keyboard laptop/PC. Kemudian pilihlah slide dïnginkan, seperti tampak pada Gambar 2.4. pada layar monitor LCD Projector/in focus. Tanyakan kepada anak "what shape is this?"

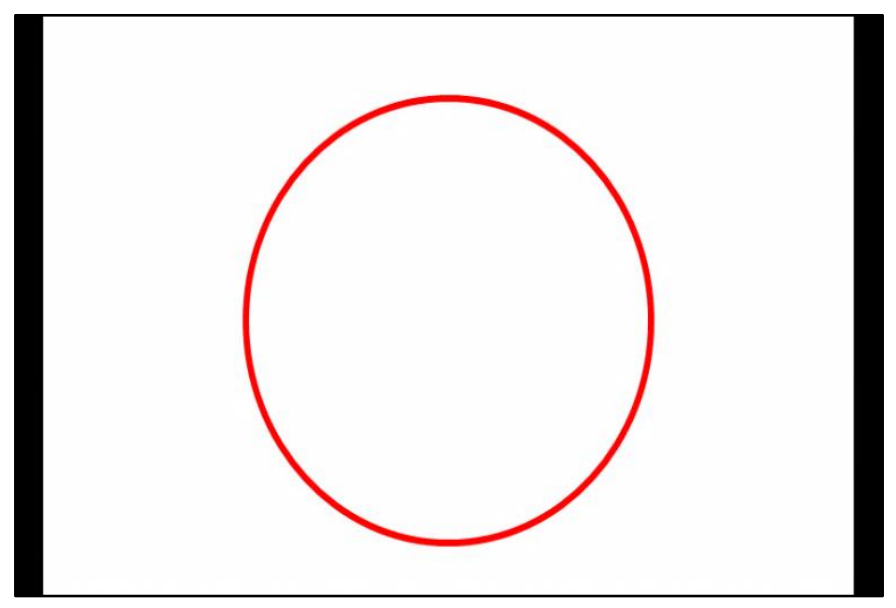

Gambar 2.4. Materi Ajar Shapes-circle

2. Langkah kedua, klik pada slide maka hasilnya akan tampak pada Gambar 2.4. Tanyakan kepada anak "what shape is this?" Biarkan anak menjawab pertanyaan tersebut sesuai dengan pengetahuan mereka.

3. Langkah ketiga, klik slide untuk memperdengarkan native sound: circleseperti tampak pada Gambar 2.5. Mintalah anak untuk mengulangi apa yang mereka dengar dari native sound tersebut. Hal ini bisa dilakukan 2-3 kali.

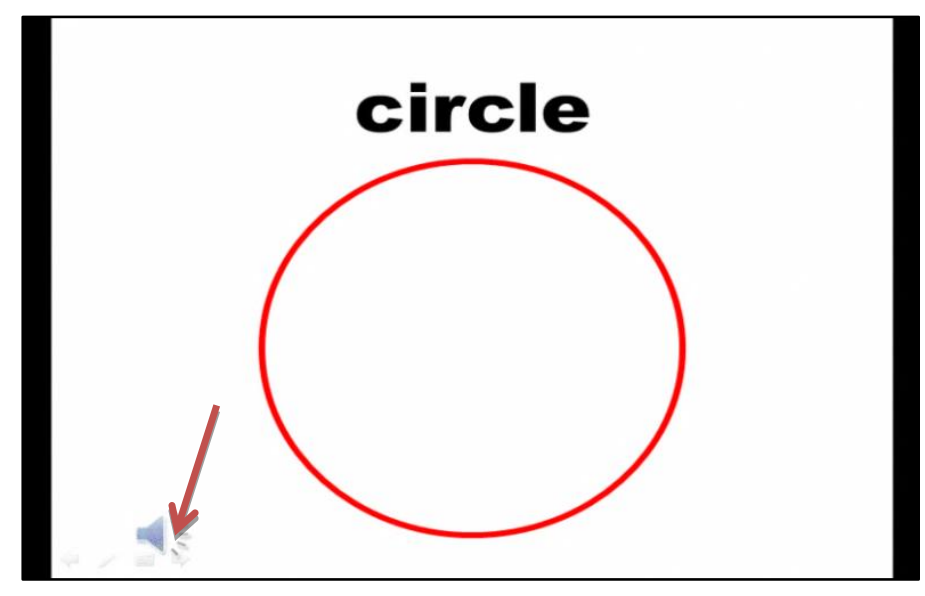

\section{Gambar 2.5. Materi Ajar Shapes-circle dengan Simbol Huruf dan Native Sound}

4. Selanjutnya, pengajar/guru meng-klik lagi slide ini untuk melanjutkan ke shape yang lainnya.

Gunakanlah langkah $1-4$ ini untuk menyampaikan materi ajar/scope yang lainnya. 
III. Tahap III: Post-test sebagai Assessment untuk mengukur penguasaan vocabulary anak Assessment (pengukuran hasil belajar) dilakukan dengan menggunakan alat ukur dan cara yang sama seperti pada Tahap I.

Melalui ketiga tahapan ini, maka akan diketahui hasil akhir penguasaan vocabulary anak sesuai dengan category yang telah ditentukan.

\section{Peubah yang diamati/diukur}

Peubah yang diukur dalam penelitian ini adalah banyaknya TRUE. Yang dimaksud dengan $\boldsymbol{T R} \boldsymbol{U} \boldsymbol{E}$ di sini adalah berapa banyak jawaban anak yang benar saat diminta untuk menyebutkan vocabulary yang ditunjuk oleh pengajar/guru secara random (acak) dari scope (color, shape, fruit, vegetable, animal, transportation, numbers up to twenty) yang sudah diajarkan dengan menggunakan alat ukur yang sudah ditentukan. Melalui alat ukur ini dapat diketahui hasil belajar anak sesuai dengan category: Fair, Good, Very Good, Excellent.

\section{Model yang Digunakan}

Model yang digunakan dalam penelitian ini adalah pengajaran vocabulary untuk anak usia dini dengan cara yang menyenangkan (learning by doing) sehingga anak tidak merasa bahwa mereka sedang belajar. Pengajaran yang menyenangkan yang digunakan adalah dengan menampilkan gambar (sesuai dengan scope) dan bagaimana pengucapan yang benar dan tepat yaitu dari native sound dengan menggunakan media pengajaran Audio-Visual yang di-download dari Google Translate.

\section{Teknik Pengumpulan Data}

Berhubung penelitian ini adalah bersifat deskriptif kuantitatif maka teknik pengumpulan data yang digunakan dalam penelitian ini adalah:

1. Hasil pre-test anak

2. Hasil post-test anak

3. Kuesioner untuk pengajar/guru 


\section{HASIL DAN PEMBAHASAN}

Analisis data dalam penelitian ini adalah:

1. Untuk Anak: dengan menggunakan category yang telah ditentukan sebelumnya, yaitu: Fair (0-25\%), Good (26-50\%), Very Good (51-75\%), atau Excellent (76-100\%).

Cara menghitung persentase tersebut adalah:

$$
\frac{T}{n} \times 100 \%=\text { category }
$$

Keterangan:

$\mathrm{T}=$ True (jawaban benar)

$\mathrm{n}=$ jumlah vocabulary dari scope yangdigunakan

2. Untuk pengajar/guru: dengan kuesioner

\section{Pendekatan yang digunakan}

Pendekatan sistematis yang digunakan dalam penelitian ini adalah survey dan observasi mengenai lokasi penelitian/sekolah, tanya jawab langsung dengan kepala sekolah atau pihak terkait, minta ijin untuk penelitian yang mana sebelumnya peneliti menjelaskan terlebih dahulu metode, media, materi ajar/lingkup (scope) yang digunakan, serta waktu/berapa lama penelitian yang digunakan. Sedangkan pendekatan teknis yang digunakan seperti yang sudah disebutkan pada bagian tahapan penelitian.

\section{Proses pengumpulan dan analisis informasi}

Proses pengumpulan dan analisis informasidalam penelitian ini adalah dengan memberikan pre-testdan post-test.

\section{Penafsiran dan penarikan kesimpulan penelitian}

Penafsiran dan penarikan kesimpulan penelitian dalam penelitian ini didapat dari hasil pre-test dan post-test dengan menggunakan category sebagai berikut: Fair (0-25\%), Good (26\%-50\%), Very Good (51\%-75\%), atau Excellent (76\%-100\%). Kemampuan anak dalam menguasai vocabulary dinyatakan: 


\begin{tabular}{|c|ll|ll|}
\hline No & \multicolumn{2}{|c|}{$\begin{array}{c}\text { Kemampuan } \\
\text { Anak }\end{array}$} & \multicolumn{3}{|c|}{ Category } \\
\hline 1 & Fair $\rightarrow$ & $\begin{array}{l}\text { jika anak dapat menyebutkan 0\%-25\% dari jumlah } \\
\text { vocabulary yang ditanyakan oleh penguji }\end{array}$ \\
\hline 2 & Good $\rightarrow$ & $\begin{array}{l}\text { jika anak dapat menyebutkan 26\%-50\% dari jumlah } \\
\text { vocabulary yang ditanyakan oleh penguji }\end{array}$ \\
\hline 3 & Very Good $\rightarrow$ & $\begin{array}{l}\text { jika anak dapat menyebutkan 51\%-75\% dari jumlah } \\
\text { vocabulary yang ditanyakan oleh penguji }\end{array}$ \\
\hline 4 & Excellent $\rightarrow$ & $\begin{array}{l}\text { jika anak dapat menyebutkan 76\%-100\% dari jumlah } \\
\text { vocabulary yang ditanyakan oleh penguji }\end{array}$ \\
\hline
\end{tabular}

\section{KESIMPULAN}

Berdasarkan hasil pre-test dan post-test, dapat disimpulkan bahwa pengajaran vocabulary bagi anak usia dini dengan menggunakan media pengajaran audio-visual yang bersumber dari Google translate:

1. Memudahkan pengajar/guru dalam mengajarkan vocabulary kepada anak karena dirancang sesuai dengan kebutuhan anak berdasarkan scope yang ada.

2. Melalui media pengajaran ini, pengajar/guru lain yang bukan berlatar belakang Pendidikan Bahasa Inggris dapat mengajar vocabulary bagi anak usia dini.

3. Belajar vocabulary lebih menyenangkan bagi anak karena ditampilkan dengan gambargambar dan warna-warna yang menarik (secara visual) dan anak belajar mendengar secara langsung pronunciation dari nativespeaker (secara audio)

4. Anak lebih tertarik untuk belajar (memorize) vocabulary.

5. Anak memilki pronunciation yang lebih baik karena meniru secara langsung dari nativespeakeryang di-download dari Google translate. 


\section{UCAPAN TERIMA KASIH}

Penulisan ini banyak melibatkan beberapa pihak yang membantu dalam penyelesaiannya sehingga penulis merasa perlu mengungkapkan apresiasi dan ucapan terima kasih kepada:

1. Drs. Sihabuddin Chalid, M.M.Pd, selaku direktur Politeknik Negeri Tanah Laut.

2. Seluruh Anggota Ikatan Guru Taman Kanak-kanak Indonesia (IGTKI) Kabupaten Tanah Laut.

3. Seluruh rekan-rekan dosen dan staff, khususnya Jurusan Teknik Informatika, Politeknik Negeri Tanah Laut.

4. Mahasiswa Teknik Informatika Tahun Akademik 2013/2014 Politeknik Negeri Tanah Laut.

\section{DAFTAR PUSTAKA}

Fadlillah, Muhammad. 2012. Desain Pembelajaran PAUD. Jogjakarta: Penerbit AR-RUZZ MEDIA

Herdiana, Widi. Perancangan Media Pembelajaran Bahasa Inggris untuk Anak Usia 5-8 Tahun. Jbptunikompp-gdl-widiherdia-30142-1-perancan-n.pdf. (Diakses 13 September 2013, jam 3.24pm).

Nurhadi, Achmad. 2012. Teaching English to Young Learners (Pengajaran Bahasa Inggris pada Anak Usia Dini). EDUCATE Journal Pendidikan Bahasa dan Sastra. Vol 1 no. 1.Juni 2012.ISSN 2301-5101. Hal.59-61

Oxford Learner's Pocket Dictionary. Fourth Edition. 2011: p.426. Oxford University Press.

Sanaky, Hujair AH. 2011. Media Pembelajaran. Yogyakarta: Penerbit KAUKAKA

Yuliyanti, Wan. 2014. Pemanfaatan Menu Insert (Audio-Visual) dari Ms. Powerpoint sebagai Media Pengajaran Vocabulary pada Anak Usia Dini. Jurnal Teknologi \& Industri.Vol 3 no. 1.Juni 2014.ISSN 2087-6920.Hal.70-77 (Addional Paper). 